\title{
THE EFFECTS OF MUSHROOM POWDER ON THE QUALITY OF CAKE
}

\author{
M. A. M. Sheikh, A. Kumar, M. M. Islam ${ }^{1 *}$ and M. S. Mahomud ${ }^{2}$ \\ Faculty of Agro-industrial and Food Process Engineering, Hajee Mohammad Danesh \\ Science and Technology University (HSTU), Dinajpur, Bangladesh
}

\begin{abstract}
The fresh mushroom and mushroom powder were analysed for their composition. Mushroom powder was incorporated in the formulations of cake at $0,5,10,15$ and $20 \%$ by weight. The effect of various levels of mushroom powder on the physico-chemical properties and nutritional quality of cakes had been observed. Mushroom powder at $15 \%$ addition level significantly improved colour, flavour and texture of cake. Cakes were also prepared by incorporating various levels $(0-20 \%)$ of mushroom powder in plane cake formulations to evaluate optimum level of powder addition. It was observed that in achieving acceptable cake quality, in terms of volume significantly higher amount (10-15\%) of mushroom powder could be incorporated in cake formulations. Compositional analysis of cake showed that cake containing mushroom powder had higher protein and fat content and lower carbohydrate content than the control cake. The cakes containing various levels of mushroom powder were evaluated for their sensory attributes by a panel of 10 tasters. The results revealed that the colour and flavour of cake containing mushroom powder was significantly different from the control cake. The texture of the cakes with mushroom powder was equally acceptable to the control cake. The overall acceptability of the cakes with mushroom powder was equally acceptable to the control cake.
\end{abstract}

Key Words: Mushroom powder, cake

\section{INTRODUCTION}

Mushrooms are simple forms of plant life which lack chlorophyll and hence can not produce their own food. They depend upon other living on dead plants and organic matter. Mushrooms are rich sources of proteins, vitamins and minerals. Low content of carbohydrate and fat makes mushrooms an ideal food for diabetes and persons who wish to shed excess fat. Mushrooms are also good source of energy about $454 \mathrm{gm}$ of fresh mushrooms providing 120 kilocalories. Most of the edible varieties of mushroom belong to the family Agaricaceae of class basibiomycetes (Srivastava and Kumar, 2002).

1 Assistant Professor, Dept. of Agricultural and Industrial Engineering, HSTU, Dinajpur, Bangladesh

2 Lecturer, Dept. of Food Engineering and Technology, HSTU, Dinajpur, Bangladesh

*Correspondence: mmi_hstu@yahoo.com 
Edible mushrooms occupy pivotal position among the lower organisms. In the developed countries, mushrooms have become one of the most important of all the horticultural crops. The production of mushrooms is increasing everywhere in the world. There are about 14000 different species of mushrooms of which at least 1450 are reported to be edible and 25 accepted widely as food (Chang and Miles, 2004).

Mushrooms can convert agro-industrial wastage to highly nutritious and protein rich foods being a food item, the nutritional values of mushrooms are considered in between meat and vegetable (Pathak et al., 1998).

Edible mushrooms have been widely utilized as human food for centuries and have been appreciated for texture and flavour as well as some medicinal and tonic attributes (Manzi et al., 2001). However, the awareness of mushrooms as a healthy food and as an important source of biological active substances with medicinal value has only recently emerged (Chang, 1996). Mushrooms are considered as healthy food because they are low in calories and fat but rich in proteins and dietary fibers (Manzi et al., 2001). Mushrooms are cooked with foods for preparing the highly nutritive soups, or it is used with other herbs as a strengthen agent. The soup or extract is consumed as a functional food. It was shown that these extracts enhanced the phagocytic activity and improved the clearance of the injected foreign proteins. Mushroom concentrates can also be freezed or spray dried to form granular powders for ease of handling and transportation. These mushrooms are available as a mixture of mushroom extracts and vitamin C crystals, or with other medicinal plants such as ginseng. Other mushrooms can be used in the manufacture of snack cake for middle aged and old people. This cake is prepared with a mixture of mushroom powders, corn flour and soybean proteins (Minzuno et al., 1995 and Salama, 2001).

Mushrooms are good source iron, copper, calcium, potassium, vitamin D, folic acid, zing, etc. Specially, selected strains of dried mushrooms are used to produce mushroom capsules and extracts. The mushroom is a highly concentrated food and unsurpassed for flavour in addition to being a completely satisfying meal (Alam and Raza, 2001).Commercial mushrooms are popular in the USA and Europe. They are used in various sausages, minsed meat, vegetables, soups, pastes and bakery products and many other dietary menus specially for flavouring purposes (Prescott and Dunne, 1959).

Nowadays, mushroom is being relished throughout the world as food and medicine. Researcher reports revealed that mushrooms are rich in food values being food source, and out of $100 \mathrm{~g}$, it contains proteins $(3.6 \mathrm{~g})$, vitamins $\mathrm{B}_{12}(0.26 \mathrm{mg})$, fats $(0.3 \mathrm{~g})$, carbohydrates $(1.5 \mathrm{~g})$, dietary fibres $(2.5 \mathrm{~g})$ and ash $(5.0 \mathrm{~g})$ and the vitamin contains are exceptionally high( Alam and Raza, 2001).

Mushrooms after harvest can be marketed as fresh, canned, dried or made into powder. Drying and canning of mushroom is essential for market from one city to another or for export purpose. Profitable mushrooms cultivation on large scale requires close attention, experience and skill (Kannaiyan and Ranasamy, 1980). 
Although the utilization of mushrooms in many types of products such as in soups, sauces, pickles etc. are popular in many countries, however, information on the use of mushroom powder in bakery products such as cakes, breads, and biscuits is very scanty. Taking the above points into consideration the present study was under taken to achieve the specific objectives is (i) to analyse the proximate composition of fresh mushroom and mushroom powder, (ii) to analyse the proximate composition of cakes incorporated with mushroom powder, (iii) to asses the effect of various levels of mushroom powder on the sensory quality of cake.

\section{MATERIALS AND METHODS}

The study was conducted in the laboratories of the Department of Food Engineering \& Technology, Food Science \& Nutrition, Food Processing \& Preservation and Agricultural Chemistry \& Biochemistry, Hajee Mohammad Danesh Science and Technology University, Dinajpur, Bangladesh.

\section{Fresh mushroom}

Fresh mushroom of oyster variety was collected from local market. The mushrooms were washed with clean water to remove dirt, sand and other undesirable materials before use.

\section{Wheat flour}

Commercial wheat flour of 'Pata' brand (12-13\% moisture and 8-9\% protein) was used for cake preparation.

\section{Chemicals, solvents and ingredients}

Chemicals and solvents used were supplied from laboratories. Wheat flour (12-13\% moisture and $8-9 \%$ protein) was commercial white flour. Eggs, Sugar, powder milk, baking powder, shortening (dalda), Mushroom powder, salt, and other ingredients were procured from the local market. High density polyethylene bags were used for package and storage of samples. Other minor ingredients were used from laboratory stocks.

\section{Preparation of Mushroom Powder}

The fresh mushrooms were processed to remove dirt and other field damaged portion. The clean and fresh mushrooms were chopped into small pieces with knife and blanched in hot water at $100^{\circ} \mathrm{C}$ for three minutes containing $2 \%$ salt and $0.01 \%$ citric acid. Then water was drained and mushrooms were spread in trays and dried in a sun up to $5-10 \%$ moisture level at $33 \pm 2^{\circ} \mathrm{C}$ for 9 hours. After cooling to room temperature, the dried mushrooms were ground into powder in a grinder then they were sieved and packaged in polythene bags and stored at room temperature for further use in the preparation of cake.

\section{Compositional analysis of mushroom powder and cake}

The fresh mushrooms, mushroom powder and cake prepared by incorporating mushroom powder were analyzed for moisture, protein, fat, ash and carbohydrate 
contents. The moisture, protein, fat, ash contents were determined as per the methods described Rangana (1994), AOAC (2000). The carbohydrate content was determined by difference, that is by subtracting the measured moisture, protein, fat, ash from 100(Pearson,1976).All the determinations were done in triplicate and the results were expressed as the average values.

\section{Product development}

\section{Formulation of cake incorporating mushroom powder}

The basic formulation of plain cake (multi-stage mixing) (Atkins, 1971) as shown in Table 1. The additions of wheat flour in the formulations were made with $5 \%, 10 \%, 15 \%$, and $20 \%$ of mushroom powder.

Table 1. Basic formulation of plain cake on $300 \mathrm{~g}$ flour basis

\begin{tabular}{lcccc}
\hline \multicolumn{1}{c}{ Ingredients } & Quantity $(\mathrm{g})$ & Ingredients & Quantity $(\mathrm{g})$ \\
\hline Wheat flour & 300 & $\begin{array}{c}\text { milk (powder) } \\
\text { or liquid milk }\end{array}$ & 40 \\
& & Salt & $300 \mathrm{ml}$ \\
Sugar (powder) & 250 & baking powder & $8-10$ \\
Butter & 200 & vanilla essence & $5 \mathrm{ml}$ \\
Egg & $3-4$ &
\end{tabular}

\section{Cake making procedures}

Cakes were prepared by wheat flour with $5 \%, 10 \%, 15 \%$, and $20 \%$ of different mushroom powder samples in the basic formulation of cake (Table) as per method of Rajchel et al., (1975). The flour, mushroom powder and other ingredient for each cake were weighed accurately and the sugar and shortening were mixed in a mixing machine for 20 minutes to produce a cream. In later stages, half of the milk, other ingredient, and finally the flour were mixed using at low speed (145 rpm) for 10 minutes to ensure even distribution of the components. The bowl was scrapped and butter was mixed for an additional two minutes at medium speed $(250 \mathrm{rpm})$. The remaining milk was added and the butter mixed at low speed for two minutes. After the bowl was scrapped, the batter was mixed an additional two minutes at medium speed. Portion of butter weighing 150 gm was scaled into pre-greased cake pan. All cakes were baked in National forced convection oven for 40 minutes at $170^{\circ} \mathrm{C}$.

\section{Chemical analysis of cakes containing Mushroom powder}

The cake containing 5\%, 10\%, $15 \%$, and $20 \%$ mushroom powders were analyzed for moisture content, protein, ash and crude fat as per the methods of AOAC (1975).Carbohydrate content of the cake samples was determined as total carbohydrate by difference method. All determinations were done in triplicate and the results were expressed as the average value. 


\section{Evaluation of cake by objective analysis}

Cake volume was initially used as an important parameter of cake quality. The cake volume was determined by seed displacement method (Ott, 1987). Moisture content was determined according to the methods outlined in AOAC (1975). The weights and specific volume of baked cakes were also measured.

\section{Subjective (sensory) evaluation of cake}

The symmetry and the characteristics of crust and crumb of the cakes supplemented with bran samples were evaluated and recorded. Cakes were evaluated organoleptically for colour, flavour, texture, and overall acceptability. A 1-9 point hedonic rating test was also performed to assess the degree of acceptability of cakes containing mushroom powder in different level. One slice from each lot of cake was presented to 10 panellists as randomly coded samples. The taste panellists were asked to rate the sample for colour, flavour, texture, and overall acceptability on a 1-9 point scale, where $9=$ Like extremely; $8=$ Like very much; $7=$ Like moderately; $6=$ Like slightly; $5=$ Neither like nor dislike; $4=$ Dislike slightly; $3=$ Dislike moderately; $2=$ Dislike very much; $1=$ Dislike extremely. The results were evaluated by Analysis of variance and Duncan's New Multiple Range Test Procedures of the Statistical Analysis System (SAS, 1985).

\section{RESULTS AND DISCUSSION}

\section{Composition of fresh mushroom}

The fresh mushrooms were analysed for moisture, protein, fat, ash and total carbohydrate contents. The results are presented in Table 2. The fresh mushrooms contained moisture $88 \%$, protein $4.20 \%$, fat $0.41 \%$, ash $1.66 \%$ and total carbohydrate $4.73 \%$. The composition of fresh mushrooms under study was more or less similar to those reported by Gupta and Sarma (2004). They reported the nutrient content of fresh mushrooms as follows: Moisture 88.15-91.64\%, protein 4.22-5.89\%, carbohydrate $4.54-4.68 \%$, fat $1.49-1.90 \%$, ash 1.6-2\%. Zakia (1976) also found that mushrooms contained water $90.9 \%$, protein $2.78 \%$, fat $0.65 \%$, and ash $0.97 \%$.

Table 2. Composition of fresh mushroom

\begin{tabular}{l|c}
\hline \multicolumn{1}{c|}{ Components } & Fresh mushroom \\
\hline Moisture (\%) & 88.00 \\
Protein (\%) & 4.20 \\
Fat (\%) & 0.41 \\
Ash (\%) & 1.66 \\
Total carbohydrate & 5.73 \\
(\% by difference) & \\
\hline
\end{tabular}

The differences observed in these compositions may be due to varietals differences, agroecological condition, fertilizer use, methods of analysis etc. 


\section{Composition of mushroom powder}

The prepared mushroom powder (Fig. 1) was slight brown in colour and was analysed for its composition. The analysis showed the composition of mushroom powder (Table 3) as moisture $10.13 \%$, protein $11.03 \%$, fat $2.92 \%$, ash $6.90 \%$, and total carbohydrate $68.02 \%$. The moisture, protein, fat and ash content were more or less similar and carbohydrate contents higher than those reported by Julita and Marek (2007). They found that dried oyster mushroom (Pleurotus ostreatus) have energy value 345Kcal, water content $10.6 \%$, protein $15.7 \%$, fat $2.66 \%$, carbohydrate $64.1 \%$ and ash $7.04 \%$.

Table 3. Composition of mushroom powder

\begin{tabular}{|c|c|}
\hline Components & Mushroom powder \\
\hline Moisture (\%) & 10.13 \\
\hline Protein $(\%)$ & 11.03 \\
\hline Fat $(\%)$ & 2.92 \\
\hline Ash (\%) & 6.90 \\
\hline Total carbohydrate by difference (\%) & 69.02 \\
\hline
\end{tabular}

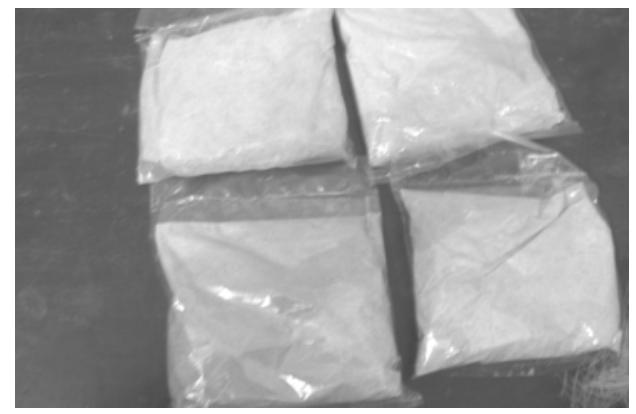

Fig. 1. Mushroom Powder

The differences observed in these compositions may be due to drying temperature, drying method, drying extent, method of analysis etc.

\section{The effects of mushroom powder on the physical properties of cakes}

Preliminary studies were carried out on the cakes prepared by incorporating $0,5,10,15 \%$, and $20 \%$ mushroom powder in the formulations. The cakes were evaluated for their weight, thickness, volume and moisture content and the result are presented in Table 4.

The weights of all the cake samples were higher than the control cakes containing no mushroom powder. The cakes containing $20 \%$ mushroom powder had the higher weight than those with $0,5,10 \%$ and $15 \%$ mushroom powder. The volume of the cakes increased with the increasing levels of mushroom powder and the control cakes had the lowest volume than those containing 5, 10, 15, 20\% mushroom powder in the formulations. 
There was very little effect of addition of mushroom powder on the thickness of the cakes. The moisture content of control cake was lower than others except $5 \%$.

Table 4 . The effects of mushroom powder in the weight, volume, thickness, and moisture content of cakes

\begin{tabular}{c|c|c|c|c|c}
\hline Cake type & $\begin{array}{c}\text { Addition of mushroom } \\
\text { powder }(\%)\end{array}$ & $\begin{array}{c}\text { Weight } \\
(\mathrm{g})\end{array}$ & $\begin{array}{c}\text { Volume } \\
(\mathrm{cc})\end{array}$ & $\begin{array}{c}\text { Thickness } \\
\mathrm{T}(\mathrm{cm})\end{array}$ & $\begin{array}{c}\text { Moisture } \\
\text { content }(\%)\end{array}$ \\
\hline Control (wheat flour) & 0 & 114 & 100 & 0.79 & 18.43 \\
Mushroom powder & 5 & 115 & 104 & 0.81 & 16.03 \\
& 10 & 116 & 107 & 0.80 & 22.19 \\
& 15 & 117 & 109 & 0.82 & 19.02 \\
& 20 & 118 & 112 & 0.81 & 20.06 \\
\hline
\end{tabular}

\section{Composition of cakes incorporated with mushroom powder}

In the present study five samples of cakes, one containing no mushroom powder and four samples with various levels of mushroom powder, were prepared and analysed for their composition. The results are shown in Table 5.

Table 5. Composition of the cakes containing different level of mushroom powder

\begin{tabular}{ll|c|c|c|c|c}
\hline Cake type & $\begin{array}{c}\text { Moisture } \\
(\%)\end{array}$ & $\begin{array}{c}\text { Protein } \\
(\%)\end{array}$ & $\begin{array}{c}\text { Fat } \\
(\%)\end{array}$ & $\begin{array}{c}\text { Ash } \\
(\%)\end{array}$ & $\begin{array}{c}\text { Total Carbohydrate } \\
\text { (by difference) } \%\end{array}$ \\
\hline Cake & 18.43 & 8.70 & 15.10 & 0.68 & 57.09 \\
& $\begin{array}{l}\text { Control (only with } \\
\text { wheat flour) }\end{array}$ & 16.04 & 9.60 & 16.63 & 1.02 & 56.71 \\
$\begin{array}{l}\text { Cake with 5\% } \\
\text { mushroom powder }\end{array}$ & 22.19 & 10.28 & 17.90 & 0.53 & 49.10 \\
$\begin{array}{l}\text { Cake with 10\% } \\
\text { mushroom powder }\end{array}$ & 19.02 & 14.68 & 18.50 & 0.76 & 50.04 \\
$\begin{array}{l}\text { Cake with 15\% } \\
\text { mushroom powder }\end{array}$ & 20.06 & 13.36 & 18.93 & 0.84 & 46.81 \\
$\begin{array}{l}\text { Cake with 20\% } \\
\text { mushroom powder }\end{array}$ & & & & \\
\hline
\end{tabular}

The cakes with $20 \%$ mushroom powder contained $20.06 \%$ moisture, $13.36 \%$ protein, $18.93 \%$ fat, $0.84 \%$ ash and $46.81 \%$ carbohydrate. Protein, fat, and ash content of cake sample with different level of mushroom powder were higher than that of control cake. Moisture content of cake sample with different level of mushroom powder was higher than that of control cake except 5\% level of mushroom powder. But carbohydrate content of control cake was higher than different level of mushroom powder cakes. With the increasing level of mushroom powder, the cakes had increasing level of protein, fat, and ash and decreasing total carbohydrate. 


\section{The effect of various levels of mushroom powder on the organoleptic properties of cakes}

The cakes were prepared by incorporation of mushroom powder (Fig. 2) at $0-20 \%$ in the formulations to evaluate the sensory qualities of cakes. A Panel of 10 tasters evaluated the colour, texture, flavour and total score of cakes. The results are presented in Table 6. It was observed that total score of cakes containing 15\% mushroom powder for colour, flavour and texture were higher than those containing various levels of mushroom powder and than control cakes.

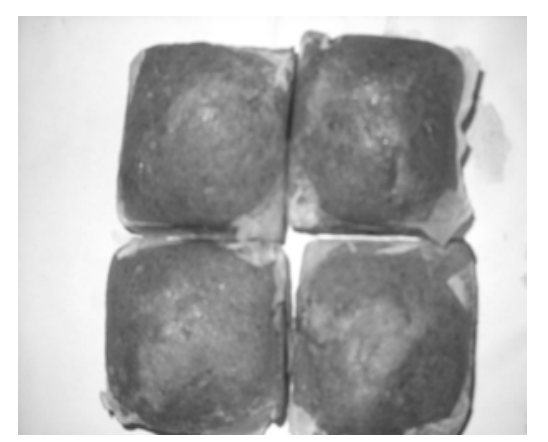

Fig. 2. Cake prepared from mushroom powder

Generally, the increasing percentage of mushroom powder gave the highest score of colour, flavour and texture up to $15 \%$ in corporation of mushroom powder but $20 \%$ incorporation of mushroom powder it was observed that total score of colour, flavour and texture was decreased with increasing level of mushroom powder. Within level of 0$20 \%$ of mushroom powder, the highest score for colour was 4.40 at $15 \%$ and lowest score of 4.11 at $20 \%$ mushroom powder. Similarly, the highest and lowest scores for texture were 4.26 and 4.14 at $15 \%$ and $20 \%$ level of mushroom powder respectively. Finally, it was observed that the cakes with $15 \%$ mushroom powder gave the highest total score of 12.88 while $20 \%$ mushroom powder gave the lowest total score of 12.25 . Generally up to $15 \%$ level of mushroom powder gave very good quality cake.

Table 6. The effect of various levels of mushroom powder on the organoleptic properties of cakes

\begin{tabular}{l|c|c|c|c|c}
\hline \multirow{2}{*}{ Cake Type } & Addition of mushroom & \multicolumn{4}{|c}{ Score on* } \\
\cline { 3 - 6 } & powder $(\%)$ & Colour & Flavour & Texture & Total Score \\
\hline Control (only wheat flour) & 0 & 4.18 & 4.11 & 4.17 & 12.46 \\
Mushroom powder & 5 & 4.16 & 4.15 & 4.19 & 12.50 \\
& 10 & 4.19 & 4.17 & 4.21 & 12.57 \\
& 15 & 4.40 & 4.22 & 4.26 & 12.88 \\
& 20 & 4.11 & 4.00 & 4.14 & 12.25 \\
\hline
\end{tabular}

*Score : 5 = Excellent; 4 = Very Good; 3 = Good; 2 = Acceptable; 1 = Poor Mean score from a panel of ten panellists 


\section{Statistical sensory evaluation of cakes}

The cakes added with $0,5,10,15$ and $20 \%$ mushroom powder were subjected to sensory evaluation by a panel of 10 tasters. The mean scores for colour, flavour, texture and overall acceptability of the cakes are presented in Table 7. A two way analysis of variance indicate that all these sensory attributes of different cakes were significantly $(P<0.05)$ different and thus the cakes samples showed varied degrees of acceptability in terms of colour, flavour, texture and overall acceptability.

Table 7. Mean sensory scores of cakes

\begin{tabular}{l|c|c|c|c}
\hline \multirow{2}{*}{ Cake type } & \multicolumn{4}{c}{ *Mean scores on sensory attributes } \\
\cline { 2 - 5 } & Colour & Flavour & Texture & Overall acceptability \\
\hline Control cake(flour only) & $6.9^{\mathrm{c}}$ & $7.1^{\mathrm{b}}$ & $8.0^{\mathrm{a}}$ & $6.9^{\mathrm{c}}$ \\
Cake with 5\% mushroom powder & $7.0^{\mathrm{b}}$ & $6.4^{\mathrm{c}}$ & $6.7^{\mathrm{b}}$ & $6.8^{\mathrm{c}}$ \\
Cake with 10\% mushroom powder & $7.0^{\mathrm{b}}$ & $6.7^{\mathrm{c}}$ & $6.4^{\mathrm{c}}$ & $7.4^{\mathrm{b}}$ \\
Cake with 15\% mushroom powder & $7.7^{\mathrm{a}}$ & $8.0^{\mathrm{a}}$ & $8.3^{\mathrm{a}}$ & $7.9^{\mathrm{a}}$ \\
Cake with 20\% mushroom powder & $6.5^{\mathrm{c}}$ & $6.7^{\mathrm{c}}$ & $6.8^{\mathrm{b}}$ & $7.5^{\mathrm{b}}$ \\
\hline
\end{tabular}

* Means with different superscripts with a column are significantly different at $\mathrm{p}<0.05$

As shown in table the DMRT test revealed that the cakes containing 15\% mushroom powder were most preferred for colour than the cake containing various levels of mushroom powder and control cake. Cake with $20 \%$ mushroom powder had least colour acceptability. The flavour, texture and overall acceptability of cake containing $15 \%$ mushroom powder were significantly different than the others.

\section{CONCLUSION}

Fresh Mushrooms were dried in a sun drying up to 5 to $10 \%$ moisture level $\left(33 \pm 2^{\circ} \mathrm{C}\right.$ for 9 hours) ground into powder. The fresh mushrooms contained moisture $88 \%$, protein $4.20 \%$, fat $0.41 \%$, ash $1.66 \%$, and total carbohydrate $5.73 \%$. Mushroom powder had moisture $10.13 \%$, protein $11.03 \%$, fat $2.92 \%$, ash $6.90 \%$, and total carbohydrate $69.02 \%$. Mushroom powder at various levels on the organoleptic properties of cakes were evaluated and revealed that colour, flavour, texture and overall acceptability of cakes varied significantly (0.05). The colour, flavour, texture and overall acceptability of cake containing $15 \%$ mushroom powder was significantly better than those of others. Analysis of composition of cake results showed that moisture content of cake sample with different level of mushroom powder was higher than that of control cake except $5 \%$ level of mushroom powder. But carbohydrate content of control cake was higher than different level of mushroom powder cakes. With the increasing level of mushroom powder, the cakes had increasing level of protein, fat, and ash and decreasing total carbohydrate.

Statistical analysis of cakes containing (0-20\%) mushroom powder that were most preferred for colour than the cake containing various levels of mushroom powder and control cake. Cake with 20\% mushroom powder had least colour acceptability. This study 
has demonstrated that addition of increasing levels of mushroom powder in the cake affected the quality attributes. The findings of the present study may help in developing commercial processing technology for effective utilisation mushroom powder especially for manufacturing of cakes.

\section{REFERENCES}

Alam, D. S. M. and Raza, M. S. 2001.Importance of Mushrooms. NIA, Tando Jam, Pakistan.

AOAC. 1975. Official Methods of Analysis, Fourteenth edition. Association of Official Analytical Chemists. Washington, DC.

AOAC. 2000. Official Methods of Analysis, Fourteenth edition. Association of Official Analytical Chemists. Washington, DC.

Atkins J. H. C. 1971. Mixing Requirement of baked Products. Fd. Manuf. 47. 120.

Chang, S. T. and Buswell, J. A. 1996. Mushroom Nutriceuticals. World J. Microbial. Biotechnical. Vol. 12: 473-476.

Chang, S. and Miles, P. G. 2004. Mushrooms, Cultivation, Nutritional Value, Medicinal Effect, and Environmental Impact, CRC Press, America.

Gupta, M. and Sarma, R. 2004. Nutrient composition of oyster mushroom grown on different substrates. J. Food Sci. Technol., 41(5): 584-586.

Julita, R and Marek, S. 2007. Dried shitake and oyster mushrooms as a good source of nutrients. Acta Sci. Pol. Technol. Aliment. 6(4): 135-142.

Kannaiyan, S. and Ramasay, K. 1980. A. Handbook of edible Mushrooms. Today and tomorrow's printers and publishers, New delhi-110005.

Manzi, P. Marconi, S. Arguzzi, A. Pizzoferrato, L. 2001. Commercial Mushrooms: nutritional quality and effect of cooking. Roma Italy-54600178.

Minzuno, 2001. Mushroom Production and Processing. p. 204.

Ott, D. B. 1987. Applied Food Science Laboratory Manual. Michigan State University. Pergnamon Press. USA.

Pathak, V. N, Yadav, N. and Gour, M. 1998, Mushroom production and processing technique agrobotanica. pp. 2-3

Pearson, D. 1976. The Dictionary of Nutrition and Food Technology $5^{\text {th }}$ edn. Butterworth Publ. London.

Pearson, B. B. 2001. Protein Fraction in edible edonian mushrooms. European Food Research and Technology. 2001; 212(4): 469-472. Berlin, Germany.

Prescott, S. C. and Dunne, C. G. 1959. Industrial Microbiology. McGraw-Hill Book Co. Inc. New York.

Rajchel. C. L. Zabik, M. E. and Everson, E. 1975. Wheat Bran and Middling: A source of dietary fibre in Bannana, Chocolate, Nut and Spices Cakes. Bakers Dig: 49. p. 27-30.

SAS. 1985. SAS user guide. Statistics, Version $5^{\text {th }}$ ed. SAS Institute. Inc. Cary, NC.

Srivastava, R. P. and Kumar, S. 2002. Fruits and vegetable Preservation, Third edition. International Book Distributing Co. Lucknow-226004, India.

Zakia, B. 1976. The nutritive value of mushrooms. Pric. First Sympo on survey and cultivation of edible mushrooms in India, Srinagar, 2: 148. 